\title{
Anion Gap 3 Measurement
}

National Cancer Institute

\section{Source}

National Cancer Institute. Anion Gap 3 Measurement. NCI Thesaurus. Code C147303.

The determination of the amount of unmeasured anions (computed as sodium minus the chloride and bicarbonate) present in a sample. 